\title{
BRASSINOSTEROIDE E ADUBAÇÃO NITROGENADA NO CRESCIMENTO E ESTADO NUTRICIONAL DE MUDAS DE ABACAXIZEIRO PROVENIENTES DO SECCIONAMENTO DE CAULE ${ }^{1}$
}

\author{
SÍLVIO DE JESUS FREITAS², PAULO CESAR DOS SANTOS ${ }^{3}$, \\ ALMY JÚNIOR CORDEIRO DE CARVALHO ${ }^{4}$, SÁVIO DA SILVA BERILLI ${ }^{5}$, \\ MARA DE MENEZES DE ASSIS GOMES 6
}

RESUMO-O objetivo deste trabalho foi verificar o efeito da adubação nitrogenada e de um análogo de brassinosteroide no crescimento e na nutrição de mudas provenientes do seccionamento do caule do abacaxizeiro 'Smooth Cayenne'. O experimento foi conduzido no delineamento em blocos casualizados, em esquema fatorial $3 \mathrm{x} 4$, sendo foram avaliados três doses de $\mathrm{N}\left(5 ; 10\right.$ e $\left.15 \mathrm{~g} \mathrm{~L}^{-1}\right)$, utilizando ureia como fonte, e quatro doses de um análogo de brassinosteroide $\left(0 ; 0,5 ; 0,75\right.$ e $\left.1,0 \mathrm{mg} \mathrm{L}^{-1}\right)$, com quatro repetições. Cada parcela experimental foi composta por 20 secções de caule. Aos 270 dias após o plantio das secções, as mudas foram colhidas e avaliadas em relação ao comprimento, diâmetro, número de folhas e à área foliar. Em seguida, as mudas foram colocadas para secar em estufa a $70^{\circ} \mathrm{C}$, para a obtenção da massa seca e análise nutricional do tecido foliar, em que se avaliaram os teores de N, K, Ca, Mg, S, Fe, Cu, Zn e Mn. O análogo de brassinosteroide promoveu incremento em todas as características de crescimento vegetativo da parte aérea das mudas de abacaxizeiro avaliadas, além de proporcionar maior teor de nitrogênio na parte aérea das mudas. A adubação nitrogenada apenas resultou em pequeno aumento do comprimento e diâmetro das mudas e não afetou o número de folhas, a área foliar, a massa seca e o estado nutricional das mudas.

Termos para indexação: Ananas comosus comosus, fitormônio, nutrição.

\section{BRASSINOSTEROID AND NITROGEN FERTILIZATION ON GROWTH AND NUTRITIONAL STATUS OF SEEDLINGS FROM PINEAPPLE SECTIONING STEM}

\begin{abstract}
The objective of this study was to investigate the effect of nitrogen fertilization and an analogue of brassinosteroid in the growth and nutrition from the sectioning stem of the pineapple 'Smooth Cayenne'. The experiment was conducted in randomized block design in a $3 \times 4$ factorial design, were evaluated three doses of $\mathrm{N}(5,10$ and $15 \mathrm{~g} \mathrm{~L}-1)$, using urea as a source, and four doses of a brassinosteroid analogue (0; $0.5,0.75$ and $1.0 \mathrm{mg} \mathrm{L}-1)$ with four replications. Each plot was composed of 20 stem sections. At 270 days after planting the seedlings were harvested and evaluated in relation to the length, diameter, leaf number and leaf area. Then the seedlings were placed to dry in an oven at $70^{\circ} \mathrm{C}$ to obtain dry mass and nutritional analysis of leaf tissue which evaluated the levels of $\mathrm{N}, \mathrm{K}, \mathrm{Ca}, \mathrm{Mg}, \mathrm{S}, \mathrm{Fe}, \mathrm{Cu}, \mathrm{Zn}$ and $\mathrm{Mn}$. The analogue of brassinosteroid promoted increment in all the characteristics of growth of the pineapple seedling evaluated, and provide higher nitrogen content in top of seedlings. Nitrogen fertilization resulted in only slight increase in the length and diameter of the seedlings and did not affect the number of leaves, leaf area, dry weight and nutritional status of the seedlings.
\end{abstract}

Index terms: Ananas comosus comosus, phytohormone, nutrition.

\footnotetext{
'(Trabalho 184-11). Recebido em: 27-06-2011. Aceito para publicação em: 29-03-2012.

${ }^{2}$ DSc em Produção Vegetal, Professor, UENF/CCTA/LFIT, 28013-603, Campos-RJ, freitassj@yahoo.com.br

${ }^{3}$ Mestrando em Produção Vegetal, UENF/CCTA/LFIT, 28013-603, Campos-RJ, pcsantos18@hotmail.com

${ }^{4}$ DSc em Produção Vegetal, Professor, UENF/CCTA/LFIT, 28013-602, Campos-RJ, almy@uenf.br

${ }^{5}$ DSc em Produção Vegetal,UENF/CCTA/LFIT, 28013-603, Campos-RJberrilli@gmail.com

${ }^{6}$ DSc em Biologia Vegetal, Técnica de nível superior, UENF/CCTA,Campos-RJ, maramag@uenf.br
} 


\section{INTRODUÇÃO}

Aárea ocupada pela abacaxicultura brasileira tem-se mantido estável nos últimos anos, com área colhida em torno de 62 mil ha (AGRIANUAL, 2010). Esta estagnação está, entre outros fatores, relacionada com os problemas fitossanitários enfrentados pelos agricultores e o manejo das mudas, um dos principais veículos de disseminação de pragas e doenças da cultura.

A situação do material de plantio do abacaxizeiro no Brasil pode ser definida como de escassez de mudas de boa qualidade, que tenham vigor e sanidade adequada para garantir um bom desenvolvimento inicial das plantas e um risco mínimo de ocorrência de doenças e pragas. Segundo Cunha e Reinhardt (2004), esta situação pode ser atribuída à baixa eficiência dos métodos, ao tempo relativamente longo para a obtenção das mudas em relação ao ciclo da cultura e ao alto custo de produção.

Estudos vêm demonstrando métodos de propagação adequados que proporcionam a obtenção de mudas sadias, de boa qualidade e em quantidade suficiente para formação de novas lavouras (COELHO et al., 2009).

Segundo Moraes et al. (2010), a muda produzida em viveiro, a partir de pedaços do caule de plantas de abacaxizeiro, é adequada para a implantação de plantios com melhor sanidade, especialmente em relação à fusariose, e também para multiplicação de novas variedades; entretanto, esta prática é muito pouco utilizada em virtude da falta de viveiristas especializados nesta atividade.

A propagação pelo seccionamento do talo é um método simples, que permite a formação de mudas através do desenvolvimento de gemas axilares de pedaços (secções) do talo da planta-mãe. As gemas passam do estado dormente para outro fisiologicamente ativo pela eliminação da ação hormonal dominante do meristema apical; no entanto, para melhorar a eficiência do método, tornam-se necessários o aprimoramento e a incorporação de novas técnicas no processo produtivo.

Os reguladores de crescimento vegetal formam um grupo bastante numeroso de compostos de uso comercial, divididos em categorias devido às variadas estruturas e efeitos. Não são encontrados naturalmente, mas exercem sobre as plantas uma ação semelhante à dos hormônios, causando respostas fisiológicas e influenciando sobre o desenvolvimento das plantas.

Os brassinosteroides (BRs) são lactonas poli-hidroxiesteroidais que ocorrem naturalmente em plantas. Segundo Gomes (2011), estas substâncias têm efeitos biológicos em baixas concentrações e são encontradas em gimnospermas, algas, monocotiledôneas e dicotiledôneas, sendo sintetizadas em diferentes órgãos das plantas, tais como folhas, botões florais, sementes, frutos, caules e raízes, podendo afetar vários processos durante o crescimento e o desenvolvimento das plantas.

Os brassinosteroides podem promover o alongamento celular, expansão celular, o gravitropismo, a resistência ao estresse, à diferenciação do xilema, e o retardamento da abscisão das folhas (FUJIOKA; SAAKURAI, 1997). Os brassinosteroides (BRs) são necessários para o crescimento normal das plantas, a deficiência na biossíntese ou na percepção destes hormônios implica plantas anãs, tipicamente verde-escuras, apresentando epinastia nas folhas com reduzida ou nenhuma fertilidade e retardo do desenvolvimento (BISHOP; KONCZ,2002).

Catunda et al. (2008) avaliaram o efeito da aplicação de concentrações de um análogo de brassinosteroide - BIOBRAS-16 (0; 0,$1 ; 0,3 ; 0,5$ e $\left.1 \mathrm{mg} \mathrm{L}^{-1}\right)$, no período de aclimatização de mudas micropropagadas de abacaxizeiro 'Imperial'. O análogo promoveu maior crescimento da parte aérea das mudas.

A nutrição e a adubação são fatores de grande relevância no processo produtivo das mudas de abacaxizeiro. Segundo Coelho et al. (2007), o fornecimento adequado de nutrientes pode proporcionar não só a redução dos gastos com fertilizantes, mas também contribui para a uniformidade e a rapidez no crescimento das mudas, reduzindo, assim, o tempo de permanência destas no viveiro.

Segundo Bregonci et al. (2008), a arquitetura do abacaxizeiro e suas características morfológicas e anatômicas favorecem a absorção foliar de nutrientes. Normalmente, as adubações foliares têm sido utilizadas para a fertilização suplementar do NK aplicado ao solo, fertilizações em épocas de baixas precipitações hídricas e para a adubação com micronutrientes.

De acordo com Coelho et al. (2007), os estudos sobre nutrição e adubação do abacaxizeiro referem-se em geral a estádios de crescimento após o plantio das mudas no campo, incluindo seus efeitos sobre a produtividade e a qualidade dos frutos obtidos. Entretanto, são escassas as informações em relação à avaliação da adubação durante a fase de viveiro.

O objetivo deste trabalho foi determinar o efeito da adubação nitrogenada e de um análogo de brassinosteroide no crescimento e na nutrição de mudas provenientes do seccionamento do caule do abacaxizeiro 'Smooth Cayenne'. 


\section{MATERIAL E MÉTODOS}

O experimento foi instalado na área da Unidade de Apoio à Pesquisa da Universidade Estadual do Norte Fluminense Darcy Ribeiro (UENF), em Campos dos Goytacazes - RJ, situada a $21^{\circ} 48^{\prime}$ de latitude sul, $41^{\circ} 20^{\prime}$ de longitude oeste e altitude de $11 \mathrm{~m}$. Foram coletadas amostras do solo na camada superficial de 0 a $20 \mathrm{~cm}$ de profundidade para análise, cujos resultados se encontram na Tabela 1 .

$\mathrm{O}$ experimento foi conduzido em delineamento em blocos casualizados, em esquema fatorial $3 \times 4$, sendo foram avaliadas três doses de N (5;10 e $15 \mathrm{~g} \mathrm{~L}^{-1}$ ), utilizando a ureia como fonte, e quatro concentrações de um análogo de brassinosteroide, o 2-alfa,3-alfa,6-oxo-5alfa-espirostanodiol ( $0 ; 0,5 ; 0,75$ e 1,0 mg L-1), com quatro repetições, sendo a parcela experimental composta de 20 secções.

Para o preparo das secções, foram utilizados caules da cultivar Smooth Cayenne, oriundos de plantações comerciais estabelecidas no município de São Francisco do Itabapoana - RJ. A coleta dos caules foi realizada logo após a colheita dos frutos, sendo selecionadas matrizes vigorosas e que não apresentavam sintomas de doenças e ataque de pragas. As plantas selecionadas foram arrancadas e, em seguida, com o auxílio de um facão, tiveram suas folhas eliminadas, com exceção das bainhas.

Após o transporte para um galpão, os caules tiveram a parte basal com presença de raízes, juntamente com o ápice eliminados, utilizando-se de uma guilhotina. A seguir, os caules foram seccionados, sendo cortados primeiro no sentido transversal ao eixo do talo em pedaços com comprimento de $10 \mathrm{~cm}$. Em seguida, foram novamente seccionados longitudinalmente, obtendo-se quatro secções.

As secções foram imediatamente tratadas por imersão em solução aquosa contendo o fungicida Cercobin 700WP (grupo químico: Benzimidazol), na concentração de $1 \mathrm{~g} \mathrm{~L}^{-1}$ e o inseticida Confidor $700 \mathrm{WG}$ (grupo químico: Cloronicotinil), na concentração de $0,03 \mathrm{~g} \mathrm{~L}^{-1}$, por cinco minutos, e a seguir colocadas para secar.

As secções foram plantadas em canteiros, na posição inclinada, com as gemas voltadas para cima, no espaçamento de $15 \mathrm{~cm}$ entre as linhas e $10 \mathrm{~cm}$ entre as secções nas linhas. A adubação e o brassinosteroide foram fornecidos via foliar.

O brassinosteroide foi aplicado em três épocas (60; 90 e 120 dias após o plantio), utilizando-se de pulverizadores manuais. Para cada época, a aplicação foi realizada em dois dias consecutivos, sendo pulverizados $100 \mathrm{~mL}$ da solução em cada parcela, cerca de $5 \mathrm{~mL}$ por secção. As parcelas que não receberam o brassinosteroide foram pulverizadas com água pura.

A fonte de nitrogênio utilizada foi a ureia. As três concentrações de nitrogênio foram fornecidas primeiramente aos 65 dias após o plantio das secções, sendo a aplicação repetida em intervalo de 30 dias até o final do experimento. $\mathrm{O}$ volume da calda pulverizado foi de $100 \mathrm{~mL}$ em cada parcela, cerca de $5 \mathrm{~mL}$ por secção.

As aplicações do brassinosteroide e da adubação nitrogenada foram realizadas sempre no final da tarde, após as 16 horas, para evitar possíveis queimaduras nas folhas das mudas.

Aos 270 dias após o plantio das secções, as mudas foram colhidas e avaliadas quanto ao comprimento, diâmetro do caule, número de folhas e à área foliar. O comprimento foi medido desde a base da muda até à extremidade da maior folha, mantendose neste momento as folhas agrupadas para cima. $\mathrm{O}$ diâmetro do caule foi medido cerca de um centímetro acima do solo, utilizando-se de um paquímetro digital, e a área foliar foi determinada mediante um medidor de área foliar (modelo LI - 3100 LICOR, Lincoln, NE, USA).

Em seguida, as mudas foram secadas em estufa a $70^{\circ} \mathrm{C}$ até peso constante, determinando-se a seguir sua massa seca e os teores de $\mathrm{N}, \mathrm{K}, \mathrm{Ca}, \mathrm{Mg}$, $\mathrm{S}, \mathrm{Fe}, \mathrm{Cu}, \mathrm{Zn}$ e $\mathrm{Mn}$ nas folhas.

Para a determinação dos teores destes nutrientes, foram pesadas duas amostras de matéria seca moída de cada tratamento para se proceder às digestões sulfúricas e nitro-perclórica. Os teores de nitrogênio foram determinados pela digestão sulfúrica, enquanto os teores de $\mathrm{K}, \mathrm{Ca}, \mathrm{Mg}, \mathrm{S}, \mathrm{Fe}$, $\mathrm{Cu}, \mathrm{Zn}$ e $\mathrm{Mn}$ foram determinados pela digestão nitroperclórica. $\mathrm{O} \mathrm{K}$ foi dosado por espectrofotometria de emissão atômica; o $\mathrm{Ca}, \mathrm{Mg}, \mathrm{Cu}, \mathrm{Fe}, \mathrm{Mn}$ e $\mathrm{Zn}$, por espectrometria de absorção atômica; o $\mathrm{S}$, por turbidimetria do sulfato. $\mathrm{O} \mathrm{N}$ orgânico foi dosado pelo método de Nessler.

Os valores obtidos para as variáveis avaliadas foram submetidos a análises de variância. As médias foram comparadas pelo teste de Tukey e submetidas à análise de regressão, a 5\% de probabilidade de erro.

\section{RESULTADOS E DISCUSSÕES}

Não houve interação significativa entre os fatores estudados. A aplicação do análogo de brassinosteroide estimulou o crescimento das mudas, conforme curvas de regressão quadrática obtidas para todas as variáveis avaliadas (Figura 1). O comprimento máximo $(37,4 \mathrm{~cm})$ foi proporcionado pela concentração estimada em $0,79 \mathrm{mg} \mathrm{L}^{-1}$, sendo $16,6 \%$ maior do que a menor média, observada nas plantas 
que não receberam o análogo do brassinosteroide .

O comprimento da muda é uma característica biométrica importante para a indicação do tamanho adequado de mudas de abacaxizeiro para plantio definitivo no campo. Reinhardt e Cunha (1999) recomendaram a altura mínima de $25 \mathrm{~cm}$ para o plantio definitivo das mudas obtidas por secções de caule. Verifica-se que todos os tratamentos, inclusive a testemunha, proporcionaram médias de comprimento de mudas adequado para irem para o campo ao final do período experimental de 270 dias.

A maior média de número de folhas $(32,2$ por planta) foi observada na concentração estimada de $0,64 \mathrm{mg} \mathrm{L}^{-1}$ de brassinosteroide, sendo que o menor número foi estimado em 30,1, no tratamentotestemunha (Figura 1). O número de folhas com desenvolvimento normal, em abacaxizeiro, é uma importante característica para a avaliação do crescimento e desenvolvimento de planta, pois tem forte correlação com a área foliar, matéria fresca e seca da parte aérea e altura de planta.

A área foliar também foi aumentada em resposta à aplicação do brassinosteroide. A concentração de $0,75 \mathrm{mg} \mathrm{L}^{-1}$ foi a que proporcionou a maior área foliar estimada, com média de $1.518 \mathrm{~cm}^{2}$, e o maior diâmetro, o que representou acréscimos de $31,7 \%$ e 17,2\% em relação à testemunha (Figura 1). E a maior massa seca da parte aérea foi obtida para a dose de $0,68 \mathrm{mg} \mathrm{L}^{-1}$ do brassinosteroide, representando incremento de $8,6 \%$ em relação à testemunha (Figura 1).

O efeito positivo de análogo de brassinosteroide - BIOBRAS-16 sobre o crescimento de mudas micropropagadas do abacaxizeiro 'Imperial' foi reportado por Catunda et al. (2008), sendo que as menores concentrações efetivas do BIOBRAS-16, relacionadas ao maior crescimento, foram 0,5 e 0,1 $\mathrm{mg} \mathrm{L} \mathrm{L}^{-1}$.

Efeitos similares do brassinosteroide têm sido mostrados para outras plantas. Wang et al. (1994) relataram o aumento da matéria seca e do número de folhas do meloeiro em função da aspersão foliar de 24-epibrasinolídeo na concentração de $0,1 \mathrm{mg} \mathrm{L}^{-1}$. Altoé et al. (2008) observaram efeito benéfico das concentrações 0,$1 ; 0,5$ e $1,00 \mathrm{mg} \mathrm{L}^{-1}$ do BIOBRAS-16 sobre o diâmetro do caule da tangerineira 'Cleópatra'.

Segundo Tanaka et al. (2003), os brassinosteroides estimulam certas enzimas que desempenham papel importante na fisiologia do crescimento, como a ativação da bomba de prótons, a síntese proteica e de ácidos nucleicos, além de induzirem uma mudança na composição de alguns aminoácidos em proteínas. Elas podem provocar mudanças na composição de ácidos graxos e nas propriedades das membranas celulares, além de aumentar a capacidade de síntese de compostos polissacarídicos que facilitam a translocação de moléculas. Desempenham, ainda, um papel dominante em relação a outros fitormônios, na medida em que regulamentam sua atividade ou sua produção.

A adubação foliar com nitrogênio na forma de ureia não afetou significativamente o número de folhas, a área foliar e a massa seca das mudas. No entanto, as doses mais alta ( $15 \mathrm{~g})$ e intermediária (10 g) determinaram aumento pequeno, mas significativo, respectivamente, sobre o comprimento e o diâmetro das mudas (Tabela 2).

Coelho et al. (2007) avaliaram a resposta das mudas do abacaxizeiro 'Smooth Cayenne' à adubação foliar com ureia, cloreto de potássio e ácido bórico, durante a fase de viveiro, empregando o sistema de seccionamento do caule. Eles verificaram efeito positivo apenas para a ureia, sendo que as maiores médias de comprimento de planta foram observadas na maior concentração testada, que foi de $10 \mathrm{~g} \mathrm{~L}^{-1}$.

Bregonci et al. (2008) também observaram maior crescimento em área foliar, altura e massa seca da parte aérea das mudas do abacaxizeiro cv. Gold em resposta a adubos foliares.

$\mathrm{O}$ efeito geral bastante pequeno sobre o crescimento das mudas do abacaxizeiro 'Smooth Cayenne' das doses de adubação nitrogenada estudadas neste trabalho pode estar relacionado com a quantidade significativa de reservas contidas nas secções dos caules, visto que estas foram retiradas de plantas-matrizes vigorosas, bem como a disponibilidade de nutrientes contidos no solo da área experimental.

Quanto ao estado nutricional das mudas, não houve interação significativa entre os tratamentos. Quando analisadas isoladamente, as doses de nitrogênio não proporcionaram diferença significativa no teor nutricional das mudas (Tabela 3).

Estes resultados concordam com os obtidos por Coelho et al. (2010), que verificaram que doses crescentes de nitrogênio $\left(0 ; 2,5 ; 5,0 ; 7,5\right.$ e $10 \mathrm{~g} \mathrm{~L}^{-1}$ de ureia) não afetaram os teores foliares de $\mathrm{N}, \mathrm{K}$, $\mathrm{Ca}, \mathrm{Mg}, \mathrm{Zn}, \mathrm{Cu}, \mathrm{Fe}$ e $\mathrm{Mn}$ em mudas do abacaxizeiro 'SmoothCayenne' provenientes do seccionamento do caule. Bregonci et al. (2008) também verificaram que o aumento da adubação nitrogenada de referência não influenciou significativamente nos teores foliares de $\mathrm{N}$ e S nas mudas micropropagadas do abacaxizeiro cv. Gold.

Por outro lado, o teor de nitrogênio na parte aérea das mudas aumentou linearmente com a elevação da concentração do brassinosteroide. A concentração mais alta estudada, de 1,0 $\mathrm{mg} \mathrm{L}^{-1}$, proporcionou incre- 
mento de $11,1 \%$ no teor de $\mathrm{N}$ em comparação com a testemunha (Figura 2).

Altoé et al. (2008) verificaram que a concentração de $1,0 \mathrm{mg} \mathrm{L}^{-1}$ do brassinosteroide, em associação com fungos micorrízicos arbusculares, proporcionou incremento de $15,4 \%$ no teor de $\mathrm{N}$ na massa seca da parte aérea de plantas da tangerineira 'Cleopatra'.

TABELA 1 - Resultados das análises químicas de amostra do solo da área experimental.

\begin{tabular}{|c|c|c|c|c|c|c|c|c|c|c|}
\hline \multirow{2}{*}{$\begin{array}{c}\mathrm{pH} \\
\mathrm{H}_{2} \mathrm{O}\end{array}$} & \multirow{2}{*}{$\begin{array}{c}\mathrm{P} \\
\mathrm{mg} \mathrm{dm^{-1 }}\end{array}$} & K & $\mathrm{Ca}$ & $\mathrm{Mg}$ & $\mathrm{Al}$ & $\mathrm{Fe}$ & $\mathrm{Cu}$ & $\mathrm{Zn}$ & $\mathrm{Mn}$ & M.O \\
\hline & & \multicolumn{4}{|c|}{$\mathrm{mmol}_{\mathrm{c}} \mathrm{dm}^{-3}$} & \multicolumn{5}{|c|}{$\mathrm{mg} \mathrm{dm}^{-3}$} \\
\hline 5,6 & 22 & 1,2 & 40 & 35 & 0 & 45 & 0,9 & 2,3 & 13 & 34 \\
\hline
\end{tabular}

Análises realizadas pelo Laboratório de Análise de Solos da Fundenor, Campos dos Goytacazes-RJ.
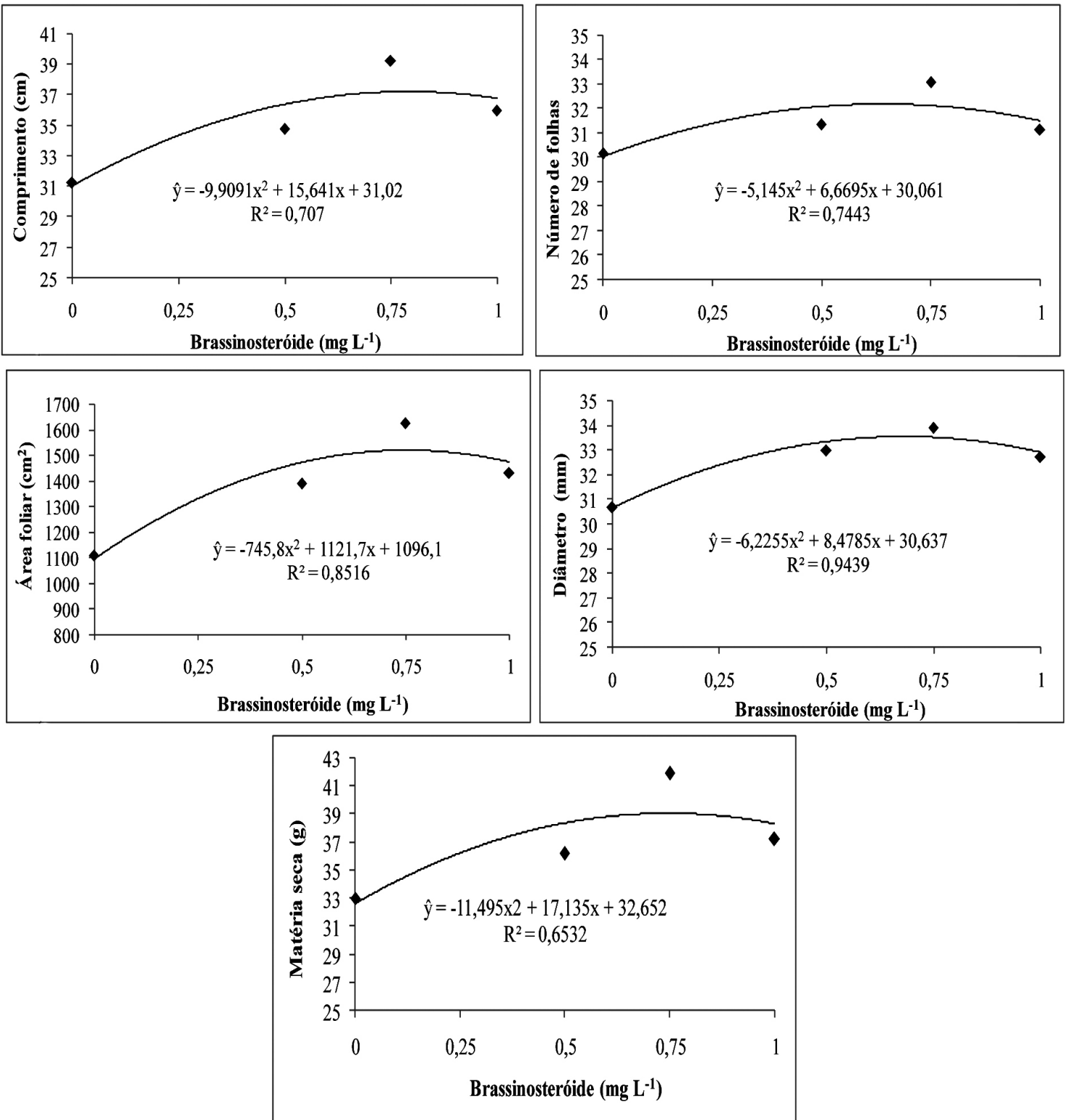

FIGURA 1 - Comprimento de mudas, número de folhas, área foliar, diâmetro e matéria seca da parte aérea de mudas de abacaxizeiro 'Smooth Cayenne', provenientes do seccionamento do caule, em resposta à aplicação de concentrações crescentes de Brassinosteroide, aos 270 dias após o plantio. 
TABELA 2 - Médias do comprimento (CMP), em cm; número de folhas (NF); diâmetro (DIAM), em mm; área foliar (AF), em cm²; e massa seca (MS), em g, de mudas de abacaxizeiro 'Smooth Cayenne' provenientes do seccionamento de caule, submetidas a doses crescentes de nitrogênio, em $\mathrm{g}$ $\mathrm{L}^{-1}$, aos 270 dias após o plantio.

\begin{tabular}{cccccc}
\hline Dose (N) & CMP & NF & DIAM & AF & MS \\
\hline 5 & $34,43 \mathrm{~b}$ & $30,82 \mathrm{a}$ & $31,35 \mathrm{~b}$ & $1396 \mathrm{a}$ & $36,41 \mathrm{a}$ \\
10 & $34,82 \mathrm{~b}$ & $31,41 \mathrm{a}$ & $33,42 \mathrm{a}$ & $1369 \mathrm{a}$ & $38,15 \mathrm{a}$ \\
15 & $36,74 \mathrm{a}$ & $32,12 \mathrm{a}$ & $32,93 \mathrm{ab}$ & $1403 \mathrm{a}$ & $36,69 \mathrm{a}$ \\
\hline Média & 35,33 & 31,45 & 32,58 & 1389 & 37,08 \\
\hline CV $(\%)$ & 5,95 & 7,66 & 6,84 & 25,11 & 20,39
\end{tabular}

Médias seguidas por letras iguais, nas colunas, não diferem entre si, pelo teste de Tukey a $5 \%$.

TABELA 3 - Teores de macronutriente $\left(\mathrm{g} \mathrm{kg}^{-1}\right)$ e micronutrientes $\left(\mathrm{mg} \mathrm{kg}^{-1}\right)$, nas folhas das mudas do abacaxizeiro ' Smooth Cayenne', aos 270 dias após o plantio, em resposta a doses de adubação nitrogenada, em $\mathrm{g} \mathrm{L}^{-1}$.

\begin{tabular}{|c|c|c|c|c|c|c|c|c|c|}
\hline Dose $(\mathrm{N})$ & $\mathrm{N}$ & $\mathrm{K}$ & $\mathrm{Ca}$ & $\mathrm{Mg}$ & $\mathrm{S}$ & $\mathrm{Zn}$ & $\mathrm{Fe}$ & $\mathrm{Mn}$ & $\mathrm{Cu}$ \\
\hline 5 & $8,0 \mathrm{a}$ & $20,6 \mathrm{a}$ & $4,0 \mathrm{a}$ & $2,5 \mathrm{a}$ & $1,5 \mathrm{a}$ & $12,9 \mathrm{a}$ & $301 \mathrm{a}$ & $105 \mathrm{a}$ & $4,5 \mathrm{a}$ \\
\hline 10 & $8,0 \mathrm{a}$ & $19,4 \mathrm{a}$ & $4,1 \mathrm{a}$ & $2,6 \mathrm{a}$ & $1,5 \mathrm{a}$ & $14,2 \mathrm{a}$ & $278 \mathrm{a}$ & $106 \mathrm{a}$ & $4,4 \mathrm{a}$ \\
\hline 15 & $8,3 \mathrm{a}$ & $19,4 \mathrm{a}$ & $4,0 \mathrm{a}$ & $2,4 \mathrm{a}$ & $1,7 \mathrm{a}$ & $14,2 \mathrm{a}$ & $315 \mathrm{a}$ & 99 a & $4,6 \mathrm{a}$ \\
\hline Média & 8,1 & 19,8 & 4,07 & 2,5 & 1,6 & 13,8 & 298 & 103 & 4,5 \\
\hline CV $(\%)$ & 10,3 & 17,7 & 29,3 & 13,0 & 13,6 & 17,4 & 16,5 & 18,6 & 13,6 \\
\hline
\end{tabular}

Médias seguidas por letras iguais, nas colunas, não diferem entre si, pelo teste de Tukey a 5\%.

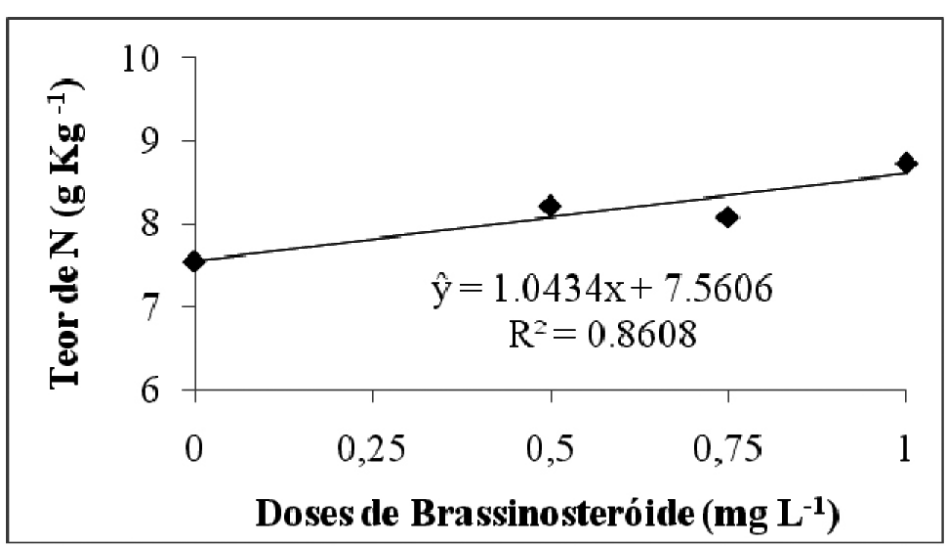

FIGURA 2 - Teor de nitrogênio nas folhas das mudas de abacaxizeiro 'Smooth Cayenne', provenientes do seccionamento do caule, em resposta à aplicação de concentrações de Brassinosteroide, aos 270 dias após o plantio. 


\section{CONCLUSÕES}

Os resultados obtidos, nas condições em que foi realizado o experimento, permitem concluir que:

1-A aplicação do análogo de brassinosteroide estimula o crescimento de mudas provenientes do seccionamento do caule do abacaxizeiro 'Smooth Cayenne' e eleva o teor de nitrogênio na parte aérea das mudas.

2-A adubação nitrogenada não apresenta efeito significativo sobre o estado nutricional das mudas, tendo efeito significativo, porém pequeno, sobre o comprimento e o diâmetro das mudas.

\section{REFERÊNCIAS}

AGRIANUAL 2010: anuário da agricultura brasileira. São Paulo: Instituto FNP, 2010. 504p.

ALTOÉ, J.A.; MARINHO, C.S.; MUNIZ, R.A.; RODRIGUES, L.A.; GOMES, M.M.A. Tangerineira 'Cleopatra' submetida à micorrização e a um análogo de brassinosteróide. Acta Scientiarum Agronomy, Maringá, v.30, n.1, p.13-17, 2008.

BISHOP, G.J.; KONCZ, C. Brassinosteroids and Plant Steroid Hormone Signaling. The Plant Cell, Norwich, v.14, p.S97-S110, 2002.

BREGONCI, I.S.; SCHMILDT, E.R.; COELHO, R.I.; REIS, E.F.; BRUM, V.J.; SANTOS, J.G. Adubação foliar com macro e micronutrientes no crescimento de mudas micropropagadas do abacaxi cv. Gold [Ananas comosus(L.) Merrill] em diferentes recipientes. Ciência e Agrotecnologia, Lavras, v.32, n.3, p.705-711, 2008.

CATUNDA, P.H.A.; MARINHO, C.S.; GOMES, M.M.A.; CARVALHO, A.J.C. de. Brassinosteroide e substratos na aclimatização do abacaxizeiro 'Imperial'. Acta Scientiarum Agronomy, Maringá, v.30, n.3, p.345-352, 2008.

COELHO, R. I.; CARVALHO, A. J. C.; MARINHO, C. S.; LOPES, J. C.; PESSANHA, P.G.O. Resposta à adubação com ureia, cloreto de potássio e ácido bórico em mudas do abacaxizeiro 'Smooth Cayenne'. Revista Brasileira de Fruticultura, Jaboticabal, v.29, n.1, p. 161-165, 2007.
COELHO, R.I.; CARVALHO, A.C.J. de; THIEBAUT, J.T.L.; LOPES, J.C. Brotação de gemas em secções de caule de abacaxizeiro Smooth Cayenne tratadas com reguladores de crescimento. Revista Brasileira de Fruticultura. Jaboticabal, v.31, n.1, p. 203-209, 2009.

COELHO, R. I.; CARVALHO, A. J. C.; THIEBAUT, J. T. L. Teores foliares de nutrientes em mudas do abacaxizeiro 'Smooth Cayenne' em resposta à adubação. Revista de Ciências Agrárias, Lisboa, v.33, n.2, p.173-179, 2010.

CUNHA, G.A.P.; REINHARDT, D.H.R.C. Manejo de mudas de abacaxi. Cruz das Almas: EMBRAPA, 2004. p.105. (Comunicado Técnico)

FUJIOKA, S.; SAKURAI, A. Biosynthesis and metabolism of brassinosteroids. Plant Physiology, Washington, v.100, n. 3, p. 710-715, 1997.

GOMES, M.M.A. Physiological effects related to brassinosteroid application in plants. In: HAYAT, S.; AHMAD, A. Brassinosteroids: a class of plant hormone. New York: Springer, 2011. p.119-142.

MORAES, A. M.; ALMEIDA, F.A.C.; BRUNO, R.L.A.; FILHO; J.C.; NUNES S.T.; GOMES J.P. Micropropagação de abacaxizeiro cv. Emepa 1. Revista Brasileira de Engenharia Agrícola e Ambiental, Campina Grande, v.14, n.9, p.932-936, 2010.

REINHARDT, H.R.C., CUNHA, G.A.P. da. Métodos de propagação. In: CABRAL, J.R.S., SOUZA, L.F. DA S. O abacaxizeiro: cultivo, agroindústria e economia. Brasília: Embrapa/Mandioca e Fruticultura, 1999. p.105-138.

TANAKA, K.; NAKAMURA, Y.; ASAMI, T.; YOSHIDA, S.; MATSUO, T.; OKAMOTO, S. Physiological roles of brassinosteroids in early growth of Arabidopsis: Brassinosteroids have a synergistic relationship with gibberellin as well as auxin in light-grown hypocotyl elongation. Journal of Plant Growth Regulation, New York, v.22, p.259-271, 2003

WANG, Y.Q.; LUO, W.H.; XU, R.J.; ZHAO, Y.J. Effect of epibrassinolide on growth and fruit quality of watermelon. Plant Physiology, Pequim, v. 30, p. 423-425, 1994. 